\title{
Cardiovascular Risk Factors in Parents of Short Children Born Small for Gestational Age
}

\author{
SANDRA W. K. DE KORT, MARIJE VAN DIJK, RUBEN H. WILLEMSEN, WIETSKE A. ESTER, LUCIE VIET, \\ YOLANDA B. DE RIJKE, AND ANITA C. S. HOKKEN-KOELEGA
}

Department of Pediatrics [S.W.K.K., M.D., R.H.W., W.A.E., A.C.S.H.-K.], Department of Clinical Chemistry [Y.B.R.], Erasmus MC-Sophia, Rotterdam, 3015 GJ, The Netherlands; RIVM [L.V.], National Institute for Public Health and the Environment, Bilthoven, 3721 MA,

The Netherlands

\begin{abstract}
Small for gestational age (SGA) children have a higher prevalence of cardiovascular risk factors at a young age. It is not known whether this increased risk is caused by their size at birth, a familial predisposition for cardiovascular disease or smallness at birth or a combination of these factors. The cardiovascular risk profile of parents of SGA children is unknown. We compared anthropometry, blood pressure, fasting serum lipid, glucose, and insulin levels of 482 parents (mean age $41 \mathrm{y}$ ) and 286 short SGA children with age- and sex-matched references. We also investigated whether these parameters correlated between parents and their offspring. Mothers had higher systolic blood pressure, fathers had a higher body mass index and parents had more frequently high fasting glucose levels than age- and sex-matched references. Children had significantly higher systolic and diastolic blood pressure than sexand height-matched references. Twenty-four percent (mothers) and $10 \%$ (fathers) were born SGA but they did not have more cardiovascular risk factors than those born appropriate for gestational age. Cardiovascular risk factors did not correlate between parents and children. In conclusion, parents of short SGA children have a modest increase in some cardiovascular risk factors but risk factors did not correlate between parents and children. (Pediatr Res 64: 91-96, 2008)
\end{abstract}

$\mathrm{E}^{\mathrm{n}}$ pidemiologic studies reported an inverse association between birth weight and risk for cardiovascular disease (CVD) in adult life (1-3). In addition, some studies described a relation between birth weight of offspring and subsequent cardiovascular mortality of the parents $(4,5)$. The exact mechanism behind these associations and the relative roles of environmental and genetic factors has not yet been elucidated. A familial component has been proposed $(4,5)$, but others could not find a family history of CVD as explanation for the higher prevalence of cardiovascular risk factors in subjects born with a lower birth weight (6). Clustering of cardiovascular risk factors within families has also been described irrespective of birth weight $(7,8)$, whereas there is a relation between birth weight of parents and offspring $(9,10)$.

Short small for gestational age (SGA) children constitute a special group within the group of low birth weight children because they did not reach a normal height. An increased prevalence of cardiovascular risk factors in short SGA chil-

Received December 4, 2007; accepted February 13, 2008

Correspondence: Sandra de Kort, M.D., Erasmus MC Sophia, Room number SB-2603, Dr. Molewaterplein 60, 3015 GJ Rotterdam, The Netherlands; e-mail: s.dekort@erasmusmc.nl

This study was supported by Novo Nordisk Farma B.V, The Netherlands. dren has been described $(11,12)$. Some parents of short SGA children were born SGA themselves $(13,14)$. It is unknown whether an increased risk for CVD in a short SGA child can be predicted by the presence of risk factors in his/her parents. We hypothesized that parents of short SGA children have an increased risk for CVD. In addition, we hypothesized that a relative high percentage of parents was born SGA themselves and that anthropometric data and cardiovascular risk factors correlate between parents and children. We, therefore evaluated in parents of short SGA children anthropometry, blood pressure, fasting serum lipids, glucose, and insulin levels, which are regarded as predictors of CVD (15). Outcome variables were compared with those of a population-based reference group.

\section{SUBJECTS AND METHODS}

Five hundred fifty-one parents (mean age 41 y, $276(50 \%)$ fathers) of 286 white short SGA children (151 (53\%) boys) were eligible for inclusion in the period between December 1999 and September 2006. In $482(87 \%)$ of these parents, anthropometric measurements were performed and $472(86 \%)$ parents filled out a questionnaire. A complete dataset (anthropometry and questionnaire) was available in 410 parents (74\%). Two children had the same mother but different fathers. Inclusion criteria for the children have previously been described (16). In short, the children were included when prepubertal, with a birth length or birth weight SD score (SDS) and actual height SDS below -2 , without signs of catch-up growth in height and without growth failure caused by other disorders. The study was approved by the Medical Ethics Committees of the participating centers and written informed consent was obtained from all parents. ${ }^{1}$

The reference group consisted of 1699 women (aged 45 (8.5) years) and 1630 men (aged 46 (8.5) years), participating in the year 2001 in a Dutch population-based health survey. The aim of this survey was to monitor risk factors or determinants of chronic disease in the general population (17). This reference group was used to calculate age- and sex-matched SD scores in the following manner: SD score $=$ (value of parent - mean for references of the same age and sex)/SD for references of the same age and sex.

Parents. Height, weight, and waist circumference were measured with the subject standing. Body mass index (BMI) was calculated. Systolic and diastolic blood pressure (BP) were measured in the nondominant arm while in a sitting position and the mean of three measurements was used for analysis. Height and weight for height were expressed as SDS using Dutch standards $(18,19)$. Waist circumference, BMI and BP were expressed as SDS adjusted for age and sex using the reference group (17). All parents were asked to fill out a questionnaire about birth characteristics, medical history, present health, and family history on CVD and DM. CVD was defined as the occurrence of myocardial infarction, cerebrovascular accident, pulmonary embolism or deep

Abbreviations: AGA, appropriate for gestational age; BP, blood pressure; CVD, cardiovascular disease; DM, diabetes mellitus; HOMA-IR, homeostatic model assessment for insulin resistance index; MS, metabolic syndrome; SGA, small for gestational age; TC, total cholesterol; TG, triglycerides 
vein thrombosis. SGA was defined as a birth length and/or birth weight SDS below -2 for gestational age (20). Fasting blood samples were available for parents of 93 children ( 92 mothers and 78 fathers). The availability of a fasting blood sample in the parents deviated from the year in which their child was included. Parents with an available fasting blood sample were comparable with those without an available blood sample with respect to all outcome variables except for age (38.7vs. $42.1 \mathrm{y}, p<0.001)$ and systolic blood pressure SDS (0.09 vs. 0.33 SDS, $p<0.05)$. Of the 92 mothers with an available blood sample, 44 had birth data and 10 were born SGA. Of the 78 fathers with an available blood sample, 33 had birth data and four were born SGA.

Children. Height, weight, head circumference, systolic, and diastolic blood pressure (BP) were measured and BMI was calculated. Height, head circumference, and BMI were expressed as SD scores adjusting for sex and age according to Dutch reference data (19), whereas BP was adjusted for sex and height (21). Fasting blood samples were available for 191 children.

Biochemical measurements. After centrifugation, all samples were frozen $\left(-80^{\circ} \mathrm{C}\right)$ until assayed. Fasting serum insulin levels were determined by chemoluminescent assay on an Immulite 2000 analyzer (Diagnostic Products Corporation, Los Angeles, CA). Fasting glucose was measured on a Hitachi 917 analyzer. HOMA-IR was calculated (22). Serum total cholesterol (TC) and triglycerides (TG) were determined enzymatically and LDL-cholesterol and HDL-cholesterol were determined using a homogeneous assay on a Hitachi 917 (Roche Diagnostics, Mannheim, Germany).

Parental fasting TC and HDL-c levels were expressed as SDS adjusted for age and sex using the reference group (17). For children, we used reference values of our hospital (Erasmus MC-Sophia) to define high TC, LDL-c, and TG levels and low HDL-c levels. Cutoff values for high total cholesterol were $\geq 5.0 \mathrm{mM}$ for age $0-3 \mathrm{y}, \geq 5.4 \mathrm{mM}$ for age $4-12 \mathrm{y}$, and $\geq 6.5 \mathrm{mM}$ for adults (23). Cutoff values for high LDL-cholesterol levels were $\geq 3.5 \mathrm{mM}$ for age $0-3 \mathrm{y} ; \geq 3.4 \mathrm{mM}$ for age $4-12$ y and $\geq 4.2 \mathrm{mM}$ for adults (23). As TG and HDL-c levels are components of the ATP III criteria, applied cutoff values for these lipids are described in the section about the definition of metabolic syndrome.

Metabolic syndrome definition. Metabolic syndrome (MS) increases the risk for CVD and DM type 2 (15). According to the Third Report of the National Cholesterol Education Program's Adult Treatment Panel (ATPIII) criteria, adults have MS when three or more of the following symptoms are present: central obesity [waist circumference $\geq 102$ (males) or $88 \mathrm{~cm}$ (females), raised TG levels (TG $\geq 1.7 \mathrm{mmol} / \mathrm{L}$ ), reduced HDL-c levels (HDL-c $<1.0$ (males) or 1.3 (females) $\mathrm{mmol} / \mathrm{L}$ ), high $\mathrm{BP}$ (systolic $\geq 130$ and/or diastolic $\mathrm{Bp} \geq 85 \mathrm{~mm} \mathrm{Hg}$ or current treatment for hypertension)], and increased fasting glucose levels (glucose $\geq 5.6 \mathrm{mmol} / \mathrm{L}$ ) (24).

In children, we used the modified ATP III criteria by Weiss et al. to diagnose MS (25). High BP was defined as a height- and sex-adjusted systolic or diastolic $\mathrm{Bp}>95$ th percentile (21). MS was diagnosed in children if three or more of the following symptoms were present: obesity (BMI $\geq 2$ SDS (19)), TG levels $>95$ th percentile $(\mathrm{TG} \geq 1.2 \mathrm{mmol} / \mathrm{L}$ for age $0-3 \mathrm{y}, \mathrm{TG} \geq 1.0$ $\mathrm{mmol} / \mathrm{L}$ for age $4-12 \mathrm{y}$ ), HDL-c levels $<5$ th percentile (HDL-c $<0.5 \mathrm{mmol} / \mathrm{L}$ for age $0-3 \mathrm{y}$ and HDL-c $<0.9 \mathrm{mmol} / \mathrm{L}$ for age $4-12 \mathrm{y}$ ), high $\mathrm{BP}$ and increased fasting glucose levels (glucose $\geq 5.6 \mathrm{mmol} / \mathrm{L}$ ).

Statistics. Analyses were performed using the statistical package SPSS (version 12.0.1; SPSS Inc., Chicago, IL) for Windows. Results are expressed as means with standard deviations for continuous data and as percentages for dichotomous or categorical variables. Because of a skewed distribution, insulin levels and HOMA-IR are expressed as median (interquartile range).
Differences between parents and references were evaluated using the twotailed one-sample $t$ test and $\chi^{2}$ test for proportions. $\chi^{2}$ tests were also used to detect associations between risk factors in children and parents. Independentsample $t$ tests were used to detect differences between subgroups of parents or children. Correlations within families (child-mother and child-father couples) were analyzed using Spearman's correlation coefficient. All analyses were performed separately for men and women. Because independent samples $t$ tests demonstrated no significant differences between boys and girls, the children were analyzed as one group.

\section{RESULTS}

Clinical characteristics. Clinical characteristics of 482 parents and 286 children are shown in Table 1. Parental height SDS and head circumference SDS were significantly lower than zero SDS $(p<0.001)$. Mothers and fathers had a relatively larger head circumference SDS compared with height SDS ( $p<0.01$ and $p<0.001$, respectively). BMI SDS of the fathers was significantly higher than zero SDS $(p<$ 0.05). Systolic BP SDS of the mothers was significantly higher $(p<0.001)$ compared with age-matched female references but diastolic BP SDS was not. BP in fathers was comparable with age- and sex-matched references. In the children, systolic and diastolic BP SDS were significantly higher compared with sexand height-matched references $(p<0.001)$.

Birth characteristics. Birth characteristics are listed in Table 2. Compared with reference values, mothers had a significantly lower birth weight SDS $(p<0.001)$. Birth length SDS was significantly lower than zero SDS in both mothers $(p<$ $0.001)$ and fathers $(p<0.05)$. Twenty-four mothers $(24 \%)$ and nine fathers (10\%) with known birth characteristics were born SGA themselves. These percentages are significantly higher than the $2.3 \%$, which is by definition the prevalence of SGA birth in live-born neonates. Even when all parents without known birth characteristics were regarded as born AGA, the prevalence of being born SGA in parents [24/275 (9\%) mothers and 9/276 (3\%) fathers] was still higher than $2.3 \%$.

Biochemical measurements. TC SD scores were significantly higher than zero SDS, i.e., compared with the median for references (Table 3). Nine percent of the mothers had high TC levels compared with $5 \%$ of the female references, but this difference was not significant $(p=0.16)$. Fifteen percent of the fathers had high TC levels compared with $7 \%$ of the male

Table 1. Clinical characteristics of parents $(n=482)$ and children $(n=286)$

\begin{tabular}{|c|c|c|c|c|c|c|}
\hline & Mothers & $p$ value & Fathers & $p$ value & Children & $p$ value \\
\hline Age (yr) & $39.7(5.0)$ & - & $42.3(5.5)$ & - & $6.4(2.4)$ & - \\
\hline Height (cm) & $163.4(6.8)$ & - & $177.0(7.1)$ & - & $106.1(13.2)$ & - \\
\hline Height SDS & $-0.8(1.1)$ & $<0.001$ & $-0.7(1.1)$ & $<0.001$ & $-3.0(0.6)$ & $<0.001$ \\
\hline $\mathrm{HC}(\mathrm{cm})$ & $54.5(1.6)$ & - & $57.2(1.6)$ & - & 49.5 (1.9) & - \\
\hline HC SDS & $-0.5(1.0)$ & $<0.001$ & $-0.3(0.9)$ & $<0.001$ & $-1.2(1.0)$ & $<0.001$ \\
\hline HC SDS-Ht SDS & $0.2(1.1)$ & $<0.01$ & $0.3(1.1)$ & $<0.001$ & $1.8(1.1)$ & $<0.001$ \\
\hline BMI & $24.9(4.8)$ & - & $26.4(3.9)$ & - & $14.1(1.2)$ & - \\
\hline BMI SDS & $0.1(1.2)$ & 0.11 & $0.2(1.1)$ & $<0.05$ & $-1.4(1.0)$ & $<0.001$ \\
\hline Waist circ. (cm) & $82.8(11.6)$ & - & $93.1(12.1)$ & - & - & - \\
\hline Waist circ. SDS & $0.0(1.1)$ & 0.74 & $-0.1(1.2)$ & 0.14 & - & - \\
\hline Systolic BP (mm Hg) & $121.5(16.2)$ & - & $131.1(16.2)$ & - & $103.5(12.8)$ & - \\
\hline Systolic BP SDS & $0.3(1.1)$ & $<0.001$ & $0.1(1.2)$ & 0.15 & $0.9(1.1)$ & $<0.001$ \\
\hline Diastolic BP (mm Hg) & $79.5(10.7)$ & - & $83.0(12.1)$ & - & $59.2(9.2)$ & - \\
\hline Diastolic BP SDS & $0.0(1.1)$ & 0.85 & $0.0(1.2)$ & 0.82 & $0.4(1.1)$ & $<0.001$ \\
\hline
\end{tabular}

Values are expressed as mean (SD); $p$ values express the difference with age- and sex-matched references.

SDS, standard deviation score; HC, head circumference; Ht, height; BMI, body mass index; BP, blood pressure. 
Table 2. Birth characteristics

\begin{tabular}{|c|c|c|c|c|c|c|}
\hline & \multicolumn{2}{|c|}{ Mothers } & \multicolumn{2}{|c|}{ Fathers } & \multicolumn{2}{|c|}{ Children } \\
\hline & $n$ & & $n$ & & $n$ & \\
\hline Gestational age & 121 & $39.3(2.1)$ & 104 & $39.4(1.7)$ & 286 & $36.2(3.7)$ \\
\hline Birth weight (kg) & 169 & $3.0(0.6)$ & 130 & $3.3(0.7)$ & 286 & $1.9(0.7)$ \\
\hline Birth weight SDS & 100 & $-0.6(1.2)^{*}$ & 87 & $-0.2(1.5)$ & 286 & $-2.3(1.0)^{*}$ \\
\hline Birth length $(\mathrm{cm})$ & 112 & $48.4(2.8)$ & 68 & $49.9(3.4)$ & 209 & $42.3(5.0)$ \\
\hline Birth length SDS & 67 & $-1.1(1.4)^{*}$ & 47 & $-0.7(1.8)^{* *}$ & 209 & $-3.1(1.5)^{*}$ \\
\hline Born SGA (\%) & 101 & $24 \%$ & 87 & $10 \%$ & 286 & $100 \%$ \\
\hline
\end{tabular}

Data expressed as mean $(\mathrm{SD}) ; \mathrm{n}=$ number of persons with available data.

Compared with gestational age- and sex-matched references: $* p<0.001 ; * * p 0.01$.

Table 3. Fasting serum lipid, glucose, and insulin levels

\begin{tabular}{lccc}
\hline & Mothers & Fathers & Children \\
\hline TC (mmol/L) & $5.3(0.9)$ & $5.6(1.0)$ & $4.1(0.8)$ \\
TC SDS & $0.5(1.1)^{*}$ & $0.4(1.1)^{* *}$ & - \\
TG (mmol/L) & $1.2(0.7)$ & $1.7(1.2)$ & $0.8(0.4)$ \\
HDL-c (mmol/L) & $1.5(0.4)$ & $1.2(0.3)$ & $1.4(0.4)$ \\
HDL-c SDS & $0.5(1.3)^{*}$ & $0.5(1.2)^{*}$ & - \\
TC/HDL-c ratio & $3.7(1.3)$ & $4.8(1.4)$ & $3.2(1.1)$ \\
LDL-c (mmol/L) & $3.1(0.9)$ & $3.5(1.0)$ & $2.3(0.7)$ \\
Glucose (mmol/L) & $4.7(1.1)$ & $4.9(0.7)$ & $4.4(0.6)$ \\
Insulin (pmol/L) & $40.8(27.8-63.2)$ & $45.7(25.5-89.4)$ & $14.0(14.0-22.8)$ \\
HOMA-IR & $0.8(0.5-1.1)$ & $0.9(0.5-1.7)$ & $0.3(0.2-0.4)$ \\
\hline
\end{tabular}

Data expressed as mean (SD) and insulin and HOMA-IR as median (interquartile range).

Compared with age- and sex-matched references: $* p<0.001 ; * * p<0.01$.

$\mathrm{TC}$, total cholesterol; $\mathrm{N}, 2.0-5.5 \mathrm{mmol} / \mathrm{L}$ (children) or $<6.5 \mathrm{mmol} / \mathrm{L}$ (adults); TG, triglycerides; $\mathrm{N}, 0.3-1.6 \mathrm{mmol} / \mathrm{L}$ (children) or $<1.7 \mathrm{mmol} / \mathrm{L}$ (adults); HDL-c, high-density lipoprotein cholesterol; N, 1.1-2.7 mmol/L (children) or $>1.0 \mathrm{mmol} / \mathrm{L}$ (male adults) or $>1.3 \mathrm{mmol} / \mathrm{L}$ (female adults); LDL-c, low-density lipoprotein cholesterol; N, 0.0-4.2 mmol/L (children) or $<4.2 \mathrm{mmol} / \mathrm{L}$ (adults); glucose $\mathrm{N}, 2.6-6.0 \mathrm{mmol} / \mathrm{L}$; insulin $\mathrm{N},<180 \mathrm{pmol} / \mathrm{L}$.

references $(p<0.05)$. HDL-c SD scores were significantly higher than zero SDS in both mothers and fathers $(p<0.001)$. Prevalence of high LDL-c was $11 \%$ in mothers and $25 \%$ in fathers. In the reference population, LDL-c, TG, and insulin were not measured. Compared with references, parents had more frequently fasting glucose levels above the ATP III cutoff level of $5.6 \mathrm{mM}$ (Table 4). Nonetheless, mean parental fasting levels of glucose, insulin, TC, TG, HDL-c, and LDL-c were all within the normal range. Median HOMA-IR was $0.8(0.5-1.1)$ in mothers, $0.9(0.5-1.7)$ in fathers and $0.3(0.2-0.4)$ in children. In the SGA children, mean fasting serum levels of TC, TG, HDL-c, and LDL-c were within the normal range (Table 3). Only one child had a TC level above the normal range.

Parents born SGA versus parents born AGA. Mothers born SGA had a significantly smaller head circumference $(-1.0$ SDS $v s .-0.3$ SDS, $p<0.01)$ and shorter stature $(-1.5$ SDS $v s . ~-0.5$ SDS, $p<0.001)$ than mothers born appropriate for gestational age (AGA). Fathers born SGA also had a larger head circumference and shorter stature than AGA fathers but these differences were not significant. Glucose and insulin levels and SD scores for waist circumference, BMI, systolic and diastolic blood pressure, TC, and HDL-c of SGA parents were not significantly different from those born AGA.

Metabolic syndrome. Table 4 shows the different components of the MS. According to the ATP III criteria, the prevalence of MS was $15 \%$ in mothers and $22 \%$ in fathers. The number of MS components in parents born SGA was not significantly different from those born AGA. There was one child (age $5 \mathrm{y}$ ) with three components of the MS (elevated blood pressure, high fasting glucose level and a low fasting HDL-c level).

Cardiovascular disease, DM type 2 and family history. One mother and four fathers had suffered from a nonlethal myocardial infarction (mother at age $44 \mathrm{y}$; fathers at ages 30 ,

Table 4. Components of metabolic syndrome according to ATP III criteria

\begin{tabular}{|c|c|c|c|c|c|c|c|c|c|c|}
\hline & \multicolumn{2}{|c|}{ Mothers } & \multicolumn{2}{|c|}{ Reference } & \multicolumn{2}{|c|}{ Fathers } & \multicolumn{2}{|c|}{ Reference } & \multicolumn{2}{|c|}{ Children } \\
\hline & $\mathrm{n}$ & $\%$ & $\%$ & $P$ value & $n$ & $\%$ & $\%$ & $P$ value & $n$ & $\%$ \\
\hline High sys BP & 229 & 23 & 20 & 0.32 & 204 & 43 & 41 & 0.70 & 271 & 13 \\
\hline High dia BP & 229 & 29 & 27 & 0.46 & 204 & 38 & 37 & 0.84 & 271 & 6 \\
\hline Central obesity & 225 & 27 & 34 & 0.43 & 199 & 19 & 21 & 0.81 & 286 & None \\
\hline High glucose & 92 & 7 & 3 & 0.05 & 78 & 19 & 8 & $<0.01$ & 153 & 5 \\
\hline Low HDL-c & 92 & 30 & 41 & $<0.05$ & 78 & 24 & 37 & $<0.05$ & 73 & 6 \\
\hline High TG & 92 & 17 & - & - & 78 & 35 & - & - & 63 & 18 \\
\hline$\geq 3$ criteria & 92 & 15 & - & - & 78 & 22 & - & - & 64 & 2 \\
\hline
\end{tabular}

$\mathrm{n}=$ number of persons; $p$ values express the difference with the reference group.

BP, blood pressure; sys, systolic; dia, diastolic; HDL-c, high-density lipoprotein cholesterol; TG, triglycerides. 
36,45 , and $52 \mathrm{y}$, respectively). One father and two mothers had had deep vein thrombosis and one mother pulmonary embolism. Sixty-three of 254 (25\%) mothers and 69 of 249 (28\%) fathers had $\geq 1$ first-degree relative with CVD. Of these relatives, CVD occurred before the age of 60 in respectively 12 of $63(19 \%)$ and 19 of $69(28 \%)$. Two mothers and one father had DM type 2, whereas $53(21 \%)$ mothers and 49 (20\%) fathers had $\geq 1$ first-degree relative with DM type 2 .

Correlations between parents and children. There was no correlation between birth weight SDS, birth length SDS, systolic and diastolic BP SDS, BMI SDS, fasting levels of lipids and insulin, and HOMA-IR within parent-child couples. Glucose levels correlated positively between mothers and children $(r=$ $0.4, p<0.01)$ and fathers and children $(r=0.3, p<0.05) . \chi^{2}$ tests showed no association between parents and children in having a glucose level $\geq 5.6 \mathrm{mmol} / \mathrm{L}$. Head circumference correlated weakly between mothers and children $(r=0.2, p<0.01)$ and fathers and children $(r=0.3, p<0.001)$.

\section{DISCUSSION}

This study shows that parents of short SGA children have a modestly higher prevalence of cardiovascular risk factors than age- and sex-matched references. Mothers had higher mean systolic blood pressure SDS, fathers had higher mean BMI SDS and parents had more frequently high fasting glucose levels. On the other hand, parents had less frequently low HDL-c levels than references. Risk factors did not correlate between parents and offspring. To the best of our knowledge, we provide the first data on cardiovascular risk factors in a large cohort of parents of short SGA children.

Our hypothesis was based on reported associations between low birth weight and cardiovascular risk, within subjects and across generations (26). The exact mechanism behind these associations is not completely understood. The fetal origins hypothesis poses that exposure to an adverse in utero environment leads to permanent programming of tissue function and an increased risk of CVD (27). Alternatively, low birth weight and adult cardiovascular disease might be independent features of a genetic predisposition to CVD $(28,29)$. There is also evidence of a nongenetic predisposition to low birth weight and adverse cardiovascular risk across a number of generations (26). Because we found only a modest increase of risk factors in parents and no correlation of risk factors between parents and children, we could not demonstrate a familial cause for an increased risk for CVD in short SGA subjects.

Systolic blood pressure of the mothers was significantly higher than that of age-matched female references. Systolic and diastolic blood pressure of the children was also higher than reference values. However, blood pressure in fathers was normal and there was no significant difference in the percentage of parents with elevated blood pressure according to the ATP III criteria (>130/85 mm Hg) compared with references. A limitation is that blood pressure was measured thrice within $10 \mathrm{~min}$ and not during $24 \mathrm{~h}$. Also, parents were significantly shorter than reference subjects. As blood pressure is known to increase with height $(30,31)$, parental blood pressure was relatively high for their shorter height.
The percentage of parents with fasting glucose levels above the ATP III cutoff level of $5.6 \mathrm{mmol} / \mathrm{L}$ was higher than in ageand sex-matched references. Higher fasting glucose levels might indicate insulin resistance, which in turn might increase the risk to develop DM and subsequently CVD (32). HOMA$\mathrm{IR}$, on the other hand, was $<1$, indicating a low level of insulin resistance $(22,33)$. The percentage of parents with a family history of DM type 2 was comparable with that in a population-based Danish cohort (34).

Parents had higher total cholesterol levels than age- and sex-matched references and fathers had significantly more frequent hypercholesterolemia. LDL-c levels were not measured in references but levels were above the normal range of our laboratory in $11 \%$ of the mothers and $25 \%$ of the fathers. On the other hand, HDL-c levels were also significantly higher in parents than in references. As HDL-c levels contribute to total cholesterol levels, the higher total cholesterol level in parents might thus be explained. This is supported by the total cholesterol/HDL-c ratio of the parents, which was slightly lower than the ratio of the white participants of the community-based Bogalusa Heart Study (35). Higher HDL-c levels are generally known to lower the risk for cardiovascular disease. Therefore, the higher total cholesterol level in the parents might not reflect an increased risk.

Prevalence of MS was $15 \%$ in mothers and $22 \%$ in fathers. Comparing the prevalence of MS between parents and the age-matched reference group was not possible because triglyceride (TG) levels were not measured in the reference group. No other study described the prevalence of MS in healthy subjects of the same age as our parents. Most reports on the prevalence of MS in Europe comprise older populations or populations with DM or CVD. For example the Dutch Hoorn study (age 50-75 y) reported a prevalence of MS of $19 \%$ in females and $26 \%$ in males (36). A German study (PROCAM study, age 36-39 y) reported a prevalence of $18 \%$ in females and $25 \%$ in males (37). In a Danish cohort of women (age $45 \mathrm{y}$ ), the prevalence of MS was $15 \%$ (34). Compared with these cohorts, the prevalence of MS in parents of short SGA children was comparable or lower.

Power calculations (alpha 0.05 and power 0.8 ) showed that correlations within parent-child couples with an $r>0.3$ were detectable for birth weight, birth length, systolic and diastolic blood pressure, BMI, head circumference, glucose and insulin levels. Thus, for these parameters there was sufficient power to detect clinically relevant correlations. We only found a correlation between parents and children with regard to glucose levels and head circumference. In contrast to previous population-based studies $(9,10,38)$, there were no correlations for birth weight or blood pressure. Lipid levels were measured in a smaller number of children. As a result, our study did not have enough power to detect correlations in lipid levels between parents and children.

A substantial proportion of parents (24\% mothers and $10 \%$ fathers) with known birth characteristics, was born SGA themselves but they did not have more cardiovascular risk factors than the parents who were born AGA. However, the absolute number of parents born SGA was small and even less of them provided a blood sample. This small number limited 
the power to detect differences between parents born SGA and parents born AGA.

Several other factors may have influenced our results. First, the parent group was relatively young. It is possible that increased risk for cardiovascular disease will be detectable when they are 10 y older. On the other hand, in the children, a higher diastolic and systolic blood pressure was already present at a mean age of $6.4 \mathrm{y}$. Second, parents with an available blood sample were younger and had a lower systolic blood pressure than parents without an available blood sample. Because analyses were performed after the collection of blood samples, we do not think there was a selection bias. Third, the references were $5 \mathrm{y}$ older than the parents. By transforming all outcome variables to SD scores before analysis, we corrected for the difference in mean age of both populations. Therefore, the difference in mean age cannot explain the absence of markedly increased cardiovascular risks.

In conclusion, parents of short SGA children have a modest increase in some cardiovascular risk factors. Mothers had higher mean systolic blood pressure SDS and fathers had a higher mean BMI SDS, whereas parents had more often high fasting glucose levels than age- and sex-matched references. On the other hand, HOMA-IR was low and parents had less frequently low HDL-c levels than references. Also, the prevalence of MS according to ATP III criteria was $15 \%$ in mothers and $22 \%$ in fathers, which is not higher than the reported prevalence. Risk factors did not correlate between parents and children and a substantial proportion of parents (24\% mothers and $10 \%$ fathers) with known birth characteristics, was born SGA themselves.

Acknowledgments. The authors thank Mrs. C. BruiningsVroombout, Mrs. J. van Nieuwkasteele, Mrs. M. HuibregtseSchouten, Mrs. J. van Houten, and Mrs. E. Lems, research nurses, for their assistance. They also greatly acknowledge the physicians of the participating centers: E.G.A.H. van Mil, Free University Hospital Amsterdam, The Netherlands; J. C. Mulder, Rijnstate Hospital, Arnhem, The Netherlands; R. J. H. Odink and J. J. J. Waelkens, Catharina Hospital, Eindhoven, The Netherlands; W. M. Bakker-van Waarde, University Medical Center Groningen, Groningen, The Netherlands; W. H. Stokvis, Leiden University Medical Center, Leiden, The Netherlands; C. Noordam, Radboud University Medical Center Nijmegen, Nijmegen, The Netherlands; C. Rongen-Westerlaken, Canisius Wilhelmina Hospital, Nijmegen, The Netherlands; N. J. T. Arends, V. H. Boonstra, D. C. van der Kaay, T. C. J. Sas, Erasmus Medical Center Sophia, Rotterdam, The Netherlands; H. M. Reeser and E. C. A. M. Houdijk, Juliana Children's Hospital, The Hague, The Netherlands; and M. Jansen, Wilhelmina Children's Hospital, Utrecht, The Netherlands.

\section{REFERENCES}

1. Valdez R, Athens MA, Thompson GH, Bradshaw BS, Stern MP 1994 Birthweight and adult health outcomes in a biethnic population in the USA. Diabetologia 37:624-631

2. Barker DJ, Hales CN, Fall CH, Osmond C, Phipps K, Clark PM 1993 Type 2 (non-insulin-dependent) diabetes mellitus, hypertension and hyperlipidaemia (syndrome X): relation to reduced fetal growth. Diabetologia 36:62-67
3. Leger J, Levy-Marchal C, Bloch J, Pinet A, Chevenne D, Porquet D, Collin D, Czernichow P 1997 Reduced final height and indications for insulin resistance in 20 year olds born small for gestational age: regional cohort study. BMJ 315:341-347

4. Davey Smith G, Hart C, Ferrell C, Upton M, Hole D, Hawthorne V, Watt G 1997 Birth weight of offspring and mortality in the Renfrew and Paisley study: prospective observational study. BMJ 315:1189-1193

5. Smith GD, Sterne J, Tynelius P, Lawlor DA, Rasmussen F 2005 Birth weight of offspring and subsequent cardiovascular mortality of the parents. Epidemiology 16:563-569

6. Jaquet D, Gaboriau A, Czernichow P, Levy-Marchal C 2000 Insulin resistance early in adulthood in subjects born with intrauterine growth retardation. J Clin Endocrinol Metab 85:1401-1406

7. Dallongeville J, Grupposo MC, Cottel D, Ferrieres J, Arveiler D, Bingham A, Ruidavets JB, Haas B, Ducimetiere P, Amouyel P 2006 Association between the metabolic syndrome and parental history of premature cardiovascular disease. Eur Heart J 27:722-728

8. Lee KE, Klein BE, Klein R 2003 Familial aggregation of components of the multiple metabolic syndrome in the Framingham Heart and Offspring Cohorts: Genetic Analysis Workshop Problem 1. BMC Genet 4:S94

9. Little RE 1987 Mother's and father's birthweight as predictors of infant birthweight. Paediatr Perinat Epidemiol 1:19-31

10. Emanuel I, Filakti H, Alberman E, Evans SJ 1992 Intergenerational studies of human birthweight from the1958 birth cohort. 1. Evidence for a multigenerational effect. Br J Obstet Gynaecol 99:67-74

11. Arends NJ, Boonstra VH, Duivenvoorden HJ, Hofman PL, Cutfield WS, HokkenKoelega AC 2005 Reduced insulin sensitivity and the presence of cardiovascular risk factors in short prepubertal children born small for gestational age (SGA). Clin Endocrinol (Oxf) 62:44-50

12. Hofman PL, Cutfield WS, Robinson EM, Bergman RN, Menon RK, Sperling MA, Gluckman PD 1997 Insulin resistance in short children with intrauterine growth retardation. J Clin Endocrinol Metab 82:402-406

13. Klebanoff MA, Meirik O, Berendes HW 1989 Second-generation consequences of small-for-dates birth. Pediatrics 84:343-347

14. Klebanoff MA, Schulsinger C, Mednick BR, Secher NJ 1997 Preterm and smallfor-gestational-age birth across generations. Am J Obstet Gynecol 176:521-526

15. Wilson PW, D'Agostino RB, Parise H, Sullivan L, Meigs JB 2005 Metabolic syndrome as a precursor of cardiovascular disease and type 2 diabetes mellitus. Circulation 112:3066-3072

16. van Dijk M, Mulder P, Houdijk M, Mulder J, Noordam K, Odink RJ, RongenWesterlaken C, Voorhoeve P, Waelkens J, Stokvis-Brantsma J, Hokken-Koelega A 2006 High serum levels of growth hormone $(\mathrm{GH})$ and insulin-like growth factor-I (IGF-I) during high-dose GH treatment in short children born small for gestational age. J Clin Endocrinol Metab 91:1390-1396

17. Viet AL, van den Hof S, Elvers LH, Ocke MC, Vossenaar M, Seidell JC, Otten F, Van Veldhuizen H 2003 [Risk factors and health evaluation Dutch population, a research on GGDen (rain arc project), annual report 2001]. RIVM rapport 260854004/2003

18. Roede 1985 The Netherlands 1980, height for age. Tijdsch Soc Gezondheidsz 63:1-34

19. Fredriks AM, van Buuren S, Burgmeijer RJ, Meulmeester JF, Beuker RJ, Brugman E, Roede MJ, Verloove-Vanhorick SP, Wit JM 2000 Continuing positive secular growth change in The Netherlands 1955-1997. Pediatr Res 47:316-323

20. Usher R, McLean F 1969 Intrauterine growth of live-born Caucasian infants at sea level: standards obtained from measurements in 7 dimensions of infants born between 25 and 44 weeks of gestation. J Pediatr 74:901-910

21. Rosner B, Prineas RJ, Loggie JM, Daniels SR 1993 Blood pressure nomograms for children and adolescents, by height, sex, and age, in the United States. J Pediatr 123:871-886

22. Levy JC, Matthews DR, Hermans MP 1998 Correct homeostasis model assessment (HOMA) evaluation uses the computer program (Letter). Diabetes Care 21:21912192

23. CBO 2006 [Multidisciplinary Directive Cardiovascular Risk Management]. Van Zuiden Communications B.V., Alphen aan den Rijn, pp 1-46

24. Grundy SM, Cleeman JI, Daniels SR, Donato KA, Eckel RH, Franklin BA, Gordon DJ, Krauss RM, Savage PJ, Smith SC Jr, Spertus JA, Costa F 2005 Diagnosis and management of the metabolic syndrome: an American Heart Association/National Heart, Lung, and Blood Institute scientific statement. Circulation 112:2735-2752

25. Weiss R, Dziura J, Burgert TS, Tamborlane WV, Taksali SE, Yeckel CW, Allen K, Lopes M, Savoye M, Morrison J, Sherwin RS, Caprio S 2004 Obesity and the metabolic syndrome in children and adolescents. N Engl J Med 350:2362-2374

26. Drake AJ, Walker BR 2004 The intergenerational effects of fetal programming: non-genomic mechanisms for the inheritance of low birth weight and cardiovascular risk. J Endocrinol 180:1-16

27. Barker DJ, Gluckman PD, Godfrey KM, Harding JE, Owens JA, Robinson JS 1993 Fetal nutrition and cardiovascular disease in adult life. Lancet 341:938-941

28. Hattersley AT, Beards F, Ballantyne E, Appleton M, Harvey R, Ellard S 1998 Mutations in the glucokinase gene of the fetus result in reduced birth weight. Nat Genet 19:268-270

29. Hattersley AT, Tooke JE 1999 The fetal insulin hypothesis: an alternative explanation of the association of low birthweight with diabetes and vascular disease. Lancet 353:1789-1792

30. Master AM, Lasser RP 1958 Relationship of the blood pressure to weight, height, and body build in apparently healthy subjects, 65-196 years of age. Am J Med Sci 235:278-289 
31. Cook NR, Gillman MW, Rosner BA, Taylor JO, Hennekens CH 1997 Prediction of young adult blood pressure from childhood blood pressure, height, and weight. J Clin Epidemiol 50:571-579

32. Facchini FS, Hua N, Abbasi F, Reaven GM 2001 Insulin resistance as a predictor of age-related diseases. J Clin Endocrinol Metab 86:3574-3578

33. Matthews DR, Hosker JP, Rudenski AS, Naylor BA, Treacher DF, Turner RC 1985 Homeostasis model assessment: insulin resistance and beta-cell function from fasting plasma glucose and insulin concentrations in man. Diabetologia 28:412-419

34. Lauenborg J, Mathiesen E, Hansen T, Glumer C, Jorgensen T, Borch-Johnsen K, Hornnes P, Pedersen O, Damm P 2005 The prevalence of the metabolic syndrome in a danish population of women with previous gestational diabetes mellitus is three-fold higher than in the general population. J Clin Endocrinol Metab 90:4004-4010
35. Frontini MG, Srinivasan SR, Xu JH, Tang R, Bond MG, Berenson G 2007 Utility of non-high-density lipoprotein cholesterol versus other lipoprotein measures in detecting subclinical atherosclerosis in young adults (The Bogalusa Heart Study). Am J Cardiol 100:64-68

36. Dekker JM, Girman C, Rhodes T, Nijpels G, Stehouwer CD, Bouter LM, Heine RJ 2005 Metabolic syndrome and 10-year cardiovascular disease risk in the Hoorn Study. Circulation 112:666-673

37. Assmann G, Guerra R, Fox G, Cullen P, Schulte H, Willett D, Grundy SM 2007 Harmonizing the definition of the metabolic syndrome: comparison of the criteria of the Adult Treatment Panel III and the International Diabetes Federation in United States American and European populations. Am J Cardiol 99:541-548

38. Leon DA, Koupil I, Mann V, Tuvemo T, Lindmark G, Mohsen R, Byberg L, Lithell H 2005 Fetal, developmental, and parental influences on childhood systolic blood pressure in 600 sib pairs: the Uppsala Family study. Circulation 112:3478-3485 